\title{
Repeated measurements of pulmonary function following spinal cord injury
}

\author{
M H Bluechardt BPHE MSc, ${ }^{1} \mathrm{M}$ Wiens BPT BSc, ${ }^{2} \mathrm{~S}$ G Thomas BSc MSc PhD,${ }^{3} \mathrm{M} \mathrm{J}$ \\ Plyley $\mathrm{PhD}^{4}$ \\ ${ }^{1}$ Faculty of Physical Activity Studies, University of Regina, Regina, Saskatchewan, \\ Canada; ${ }^{2}$ Department of Physiotherapy, Lyndhurst Hospital, Toronto, Ontario, Canada; \\ ${ }^{3}$ Department of Rehabilitation Medicine, University of Toronto, Toronto, Ontario, \\ Canada; ${ }^{4}$ School of Physical and Health Education, University of Toronto, Toronto, \\ Ontario, Canada.
}

Twelve subjects (11 males, 1 female) with complete spinal cord lesion (level of lesion ranging from $\mathrm{C} 4$ to $\mathrm{T} 10)$, with a mean age of 23.5 years participated in pulmonary function testing (PFT). Inspiratory and expiratory flow measurements were made at 2-month intervals from 25 to 351 days post injury. The values were interpolated and extrapolated to common dates to facilitate comparison. The effect of time on pulmonary function was determined by a repeated measures ANOVA. Forced expiratory volume in 1 second (FEV1.0) significantly increased during the course of the study $(40 \%, p<0.05)$, but increases in forced vital capacity (FVC) $(32.5 \%)$ and maximal voluntary ventilation (MVV) $(16 \%)$ were not statistically significant. Lesion level was found to be correlated (Spearman Product Moment Correlation) with pulmonary function if a single measure was made ( $r=0.55$ to 0.73 ), but emerged as a stronger predictor if the average of several repeated PFTs was correlated with lesion level $(r=0.74$ to $0.84)$. In addition, lesion level was not correlated with the amount of improvement attained during the time period studied.

We conclude that the time course of recovery of pulmonary function is variable between individuals with spinal cord injuries and can only be weakly predicted by knowledge of the initial value and the lesion level.

Keywords: spinal cord injury; lung volume measurements; respiratory function tests.

\section{Introduction}

Cervical and thoracic lesions of the spinal cord result in a varying degree of paralysis of the respiratory muscles. The effect of paralysis on pulmonary function has been the subject of a number of investigations. ${ }^{1-7}$ Ledsome and Sharpe ${ }^{6}$ measured the pulmonary function of acute quadriplegics and found a rapid improvement in forced vital capacity (FVC) from week 3 to 5 post injury with a more gradual improvement from 5 weeks to 5 months. Axen ${ }^{1}$ states that the rate of change in vital capacity (VC) decreases with advancing time post injury. Haas $^{3}$ suggests that improvement in pulmonary function tends to stabilise after 6 months.

The present study represents a prospec- tive view of the temporal effects of spinal cord injury on pulmonary function. The objectives of the study are to supplement temporal information presently in the literature, ${ }^{5}$ and to determine if there is a correlation of PFT values with the level of lesion or the time post injury.

\section{Methods}

The subjects (Table I) for this study were quadriplegics and paraplegics with complete motor and sensory lesion, resulting in some degree of respiratory muscle paralysis (ie intercostals and/or abdominal muscles). Lesion levels ranged from $\mathrm{C} 4$ to T10. All subjects were medically stable at the time of entry into the study. Informed consent was 
Table I Characteristics of subjects

\begin{tabular}{llcccc}
\hline Subject & Lesion level & Age $(\mathrm{yrs})$ & Height $(\mathrm{cm})$ & Gender & Smoker \\
\hline 1 & C4 & 16 & 178 & $\mathrm{M}$ & $\mathrm{N}$ \\
2 & C4, 5 & 20 & 184 & $\mathrm{M}$ & $\mathrm{N}$ \\
3 & C5 & 22 & 175 & $\mathrm{M}$ & $\mathrm{Y}$ \\
4 & C5 & 18 & 170 & $\mathrm{M}$ & $\mathrm{N}$ \\
5 & C5, 6 & 16 & 180 & $\mathrm{M}$ & $\mathrm{N}$ \\
6 & C5, 6 & 29 & 178 & $\mathrm{M}$ & $\mathrm{N}$ \\
7 & C6 & 29 & 175 & $\mathrm{M}$ & $\mathrm{Y}$ \\
8 & C6, 7 & 30 & 183 & $\mathrm{M}$ & $\mathrm{Y}$ \\
9 & C7, T1 & 38 & 170 & $\mathrm{M}$ & $\mathrm{Y}$ \\
10 & T5, 6 & 24 & 183 & $\mathrm{M}$ & $\mathrm{Y}$ \\
11 & T8 & 23 & 173 & $\mathrm{M}$ & $\mathrm{N}$ \\
12 & T10 & 17 & 157 & $\mathrm{~F}$ & $\mathrm{Y}$ \\
\hline
\end{tabular}

obtained from all participants. Eighteen subjects entered into the study. Statistical analysis was based on the 12 subjects who completed 3 or more test sessions. Measurements were made from 25 to 351 days post injury over the 10 month observation period.

Subjects were tested at approximately 2-month intervals, and at approximately the same time of day for each test session. All measures were conducted by a single investigator. The subject completed 3 trials for each test and the best effort was recorded. All tests were conducted with subjects sitting in their wheelchair.

The tests were performed using an 8-litre Collins Survey Spirometer and an Eagle II Microcomputer. The tests were: (1) forced vital capacity (FVC); (2) inspiratory vital capacity (IVC); and (3) maximal voluntary ventilation (MVV). The following test results were calculated from the above 3 test procedures: (1) forced vital capacity (FVC); (2) forced expiratory volume 1 second (FEV1); (3) forced expiratory volume 3 seconds (FEV3); (4) peak expiratory flow rate (PEFR) (litre/second); (5) maximal voluntary ventilation (MVV), over a 12second period. The following test results were calculated from the tracing: (1) forced inspiratory vital capacity (FIVC); (2) expiratory reserve volume (ERV); (3) inspiratory reserve volume (IRV); and (4) tidal volume (TV).

Each session began with the completion of a subjective data information sheet. The following questions were asked, and re- sponses recorded by the investigator: (1) medication change since last respiratory test session; (2) suffering from any illness or infections; (3) use of an abdominal binder; (4) physical activity or exercise that day; (5) general feeling of fatigue; (6) change in the level of abnormal muscle tone; (7) level of participation in therapy; (8) state of subject's general wellbeing.

The testing was carried out at Lyndhurst Rehabilitation Hospital (Physiotherapy Department), Toronto, Ontario.

Relationships between variables were quantified using Spearman Correlation Coefficients. The statistical significance of differences was tested with paired $t$-test $(p<0.05)$. Repeated measures ANOVA was used to test the effect of time on each variable.

\section{Results}

The pulmonary function results from the initial testing are summarized in Table II. The reduced vital capacity and slower flow rates (approximately $40 \%$ of predicted values,$^{8}$ ) are typical of the restrictive pulmonary function observed in quadriplegia. The FEV1/FVC ratio was above 0.8 (mean 0.83 ) in all subjects indicating that no obstructive pathology was present in our subjects. Correlations among measures of expiratory flow were high (FEV1-FEV3 $r=0.83$, FEV1-PEFR $r=0.74$ ) as was the correlation between the inspiratory and expiratory vital capacities $(r=0.93)$. As a consequence only the FEV1, and FVC will 
Table II Pulmonary function data $(n=12)$ from initial test

\begin{tabular}{llccc}
\hline Variable & & Mean & Range & SD \\
\hline FVC & Actual & 1.99 & $0.75-3.33$ & 0.65 \\
& \% Pred & 40 & $13-70$ & 14 \\
FIVC & Actual & 2.00 & $0.92-3.22$ & 0.62 \\
& \% Pred & 40 & $15-68$ & 14 \\
FEV1 & Actual & 1.61 & $0.72-2.95$ & 0.62 \\
& \% Pred & 40 & $15-80$ & 18 \\
FEV3 & Actual & 1.94 & $0.72-3.24$ & 0.64 \\
& \% Pred & 40 & $13-71$ & 14 \\
PEFR & Actual & 3.16 & $1.06-5.40$ & 1.35 \\
& \% Pred & 41 & $11-122$ & 30 \\
MVV & Actual & 72 & $25-146$ & 31 \\
& \% Pred & 49 & $15-91$ & 21 \\
\hline
\end{tabular}

be presented in subsequent analyses. MVV reflects both the dimensions of the pulmonary system and the ability to use respiratory muscles to generate flow. MVV was related to FEV1 $(r=0.74)$ which suggests that flow resistance remained an important determinant of integrated ventilatory function.

The coefficient of variation in 3 repeated trials was $6 \%$ for $\mathrm{FEV} 1,7 \%$ for $\mathrm{FVC}$, and $12 \%$ for MVV. The intra-subject stability of these values, within a given test session, suggests that changes greater than $10 \%$ for FEV1 and FVC and greater than $15 \%$ for MVV represent a real change in function.

On average the first test was conducted 81 days post injury. Our primary interest was in observing how pulmonary function changed during the rehabilitation period (approximately 7 months). As Figures 1, 2, and 3 indicate, there was considerable variability in the profile of recovery. Values have been interpolated or extrapolated to common dates within the range 90 to 120 days post

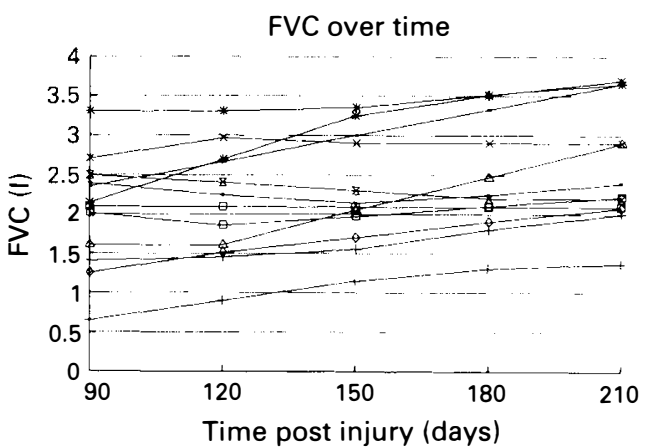

Figure 2 Profile of intra-subject change in FVC during the rehabilitation period.

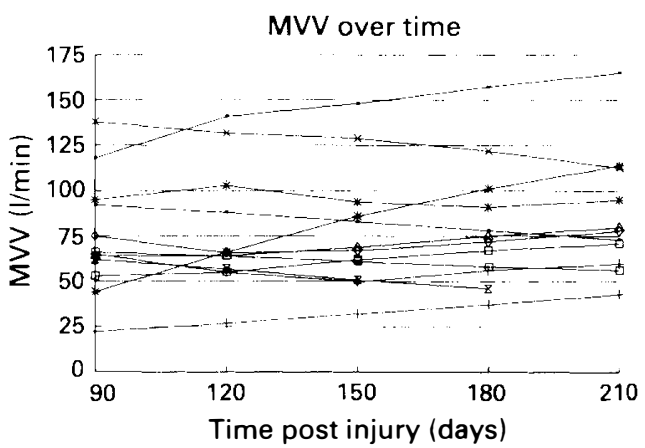

Figure 3 Profile of intra-subject change in MVV during the rehabilitation period.
Figure 1 Profile of intra-subject change in FEV
1.0 during the rehabilitation period.

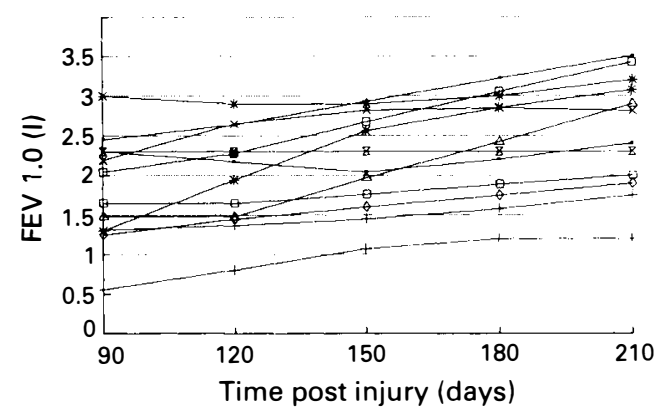


injury to facilitate comparisons. Values were not interpolated or extrapolated more than 35 days.

Some variability in the time course of recovery may be due to ill health on the testing day. In 20 cases out of 48 subject-test occurrences subjects suffered from bladder infections $(n=15)$, influenza or colds $(n=5)$ on or about the days of testing. As indicated in Table III repeated measures ANOVA indicated that there was a significant increase in FEV1 $(p \leqslant 0.001)$, but not FVC $(p \leqslant 0.07)$ or MVV $(p \leqslant 0.33)$ over the time period studied. The mean increase in FEV1 from 90-210 days post injury was
0.72 litres or $40 \%$. Nonsignificant changes were approximately $32.5 \%$ for FVC and $16 \%$ in MVV. Figures 4,5 and 6 provide a comparison of the differences observed between the first and best measures of each variable. The variability observed is due in part to improvement over the study period and to variation in performance and measurement error.

The role of lesion level in determining pulmonary function was examined through the correlation between lesion level and predicted values of FEV1, FVC, and MVV at the initial test and on average from all tests. These analyses provided an indication

Table III Time course of change in pulmonary function following spinal cord injury in 12 individuals. Values are linear interpolations between the nearest measures. Linear extrapolation of less than 30 days was required in 3 cases. Values are means and standard deviation and represent between-subject variability at each time point

\begin{tabular}{|c|c|c|c|c|c|c|}
\hline \multirow[t]{2}{*}{ Variable } & & \multicolumn{5}{|c|}{ Time post injury (days) } \\
\hline & & 90 & 120 & 150 & 180 & 210 \\
\hline FEV1 (1) & & $\begin{array}{c}1.82 \\
(0.68)\end{array}$ & $\begin{array}{c}1.97 \\
(0.63)\end{array}$ & $\begin{array}{c}2.17 \\
(0.62)\end{array}$ & $\begin{array}{c}2.36 \\
(0.65)\end{array}$ & $\begin{array}{c}2.54 \\
(0.73)\end{array}$ \\
\hline & $\%$ Pred & 45 & 49 & 54 & 59 & 63 \\
\hline FVC (1) & & $\begin{array}{c}2.03 \\
(0.72)\end{array}$ & $\begin{array}{c}2.14 \\
(0.70)\end{array}$ & $\begin{array}{c}2.29 \\
(0.70)\end{array}$ & $\begin{array}{c}2.45 \\
(0.71)\end{array}$ & $\begin{array}{c}2.69 \\
(0.80)\end{array}$ \\
\hline & $\%$ Pred & 41 & 43 & 46 & 49 & 54 \\
\hline $\operatorname{MVV}(1 / \min )$ & & $\begin{array}{c}74 \\
(32)\end{array}$ & $\begin{array}{c}76 \\
(34)\end{array}$ & $\begin{array}{c}78 \\
(33)\end{array}$ & $\begin{array}{c}80 \\
(34)\end{array}$ & $\begin{array}{c}86 \\
(34)\end{array}$ \\
\hline & $\%$ Pred & 51 & 53 & 53 & 55 & 59 \\
\hline
\end{tabular}

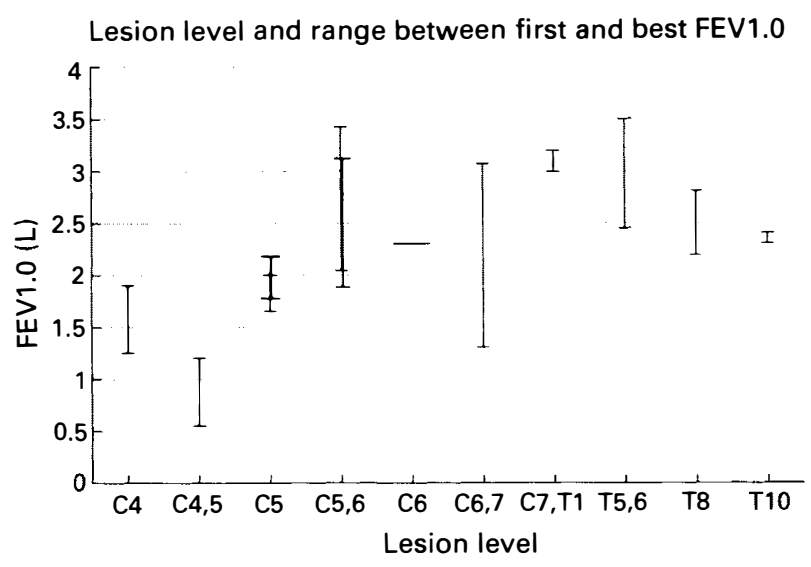

Figure 4 
Lesion level and range between first and best FVC

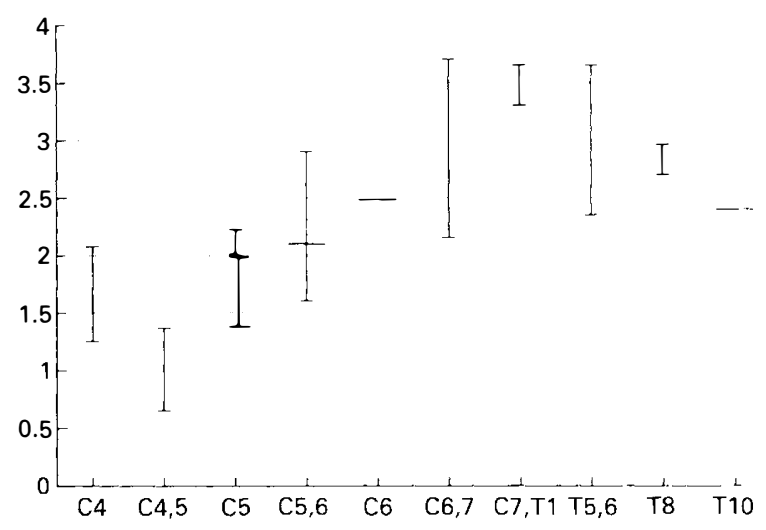

Figure 5

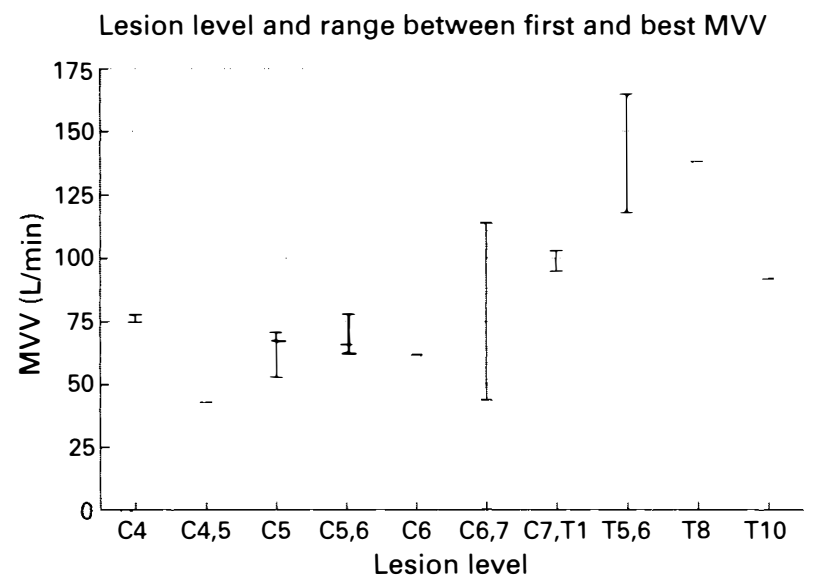

Figure 6

of the difference between a single measure and repeated trials from several days. As Table IV indicates, correlations were stronger when the average value from repeated trials was correlated with the lesion level. This may indicate that the measurement error associated with a single measure attenuates the observed correlation. ${ }^{9}$ As Figures 4, 5, and 6 illustrate, there is a clear indication that pulmonary function is reduced as the lesion occurs at a higher level. However a significant relation between the amount of improvement and the lesion level was not observed.

Subjective data were collected at the time of each test. The following variables were examined: average physiotherapy attend-
Table IV Spearman Rank Corporation between lesion level ranking and pulmonary function. (Spearman Correlation Coefficient and probability)

\begin{tabular}{cccc}
\hline & $\begin{array}{c}\text { Initial/ } \\
\text { Pred FVC }\end{array}$ & $\begin{array}{c}\text { Initial/ } \\
\text { Pred FEV1 }\end{array}$ & $\begin{array}{c}\text { Initial/ } \\
\text { Pred MVV }\end{array}$ \\
\hline $\begin{array}{c}\text { Lesion } \\
\text { level } \\
\text { Rank }\end{array}$ & $\begin{array}{c}0.73 \\
(0.007)\end{array}$ & $\begin{array}{c}0.55 \\
(0.06)\end{array}$ & $\begin{array}{c}0.56 \\
(0.06)\end{array}$ \\
\hline & $\begin{array}{c}\text { Avg/Pred } \\
\text { FVC }\end{array}$ & $\begin{array}{c}\text { Avg/Pred } \\
\text { FEV1 }\end{array}$ & $\begin{array}{c}\text { Avg/Pred } \\
\text { MVV }\end{array}$ \\
\hline $\begin{array}{c}\text { Lesion } \\
\text { level }\end{array}$ & 0.84 & 0.81 & 0.74 \\
\begin{tabular}{c} 
Rank \\
\hline
\end{tabular} & $(0.001)$ & $(0.001)$ & $(0.006)$ \\
\hline
\end{tabular}


ances per month; respiratory complications and interventions in acute care; medications (type and dosage) taken on the day of testing; illness on the day of testing; smoking history; and general activity level (as reported by the attending physiotherapist). Three subjects who improved less than $20 \%$ in FVC were compared with 9 subjects who improved $20 \%$ or more in FVC. Although the average attendances and the time spent in physiotherapy was comparable between the two groups, the general activity level was lower in the group of 3 subjects. There were no other differences in the other variables.

Five of the group of 9 who improved were motivated to improve their general performance level by engaging in endurance activities such as long distance wheelchair propulsion and arm ergometry. The subject with lesion level $\mathrm{C} 4$ developed his own breathing exercises after having been shown the technique of glossopharyngeal breathing. It would appear that motivation was an important factor. The subjective data compiled, however, were inadequate to demonstrate any true significance of this variable.

\section{Discussion}

An objective of this study was to determine the relationship between PFT values and the level of lesion. The question regarding lesion level as a predictor of expected PFT values is addressed in Figures 4, 5, and 6 which demonstrate values of FEV1, FVC and MVV as a function of lesion level. In general, the high cervical lesions function at a lower level than the lower cervical lesions. The thoracic lesions, however, do not perform at a higher level than the low cervical lesions. This may be due to associated thoracic lesions. ${ }^{7}$ It appears, therefore, that lesion level is only a rough predictor of PFT values.

The amount of improvement does not appear to be affected by the level of the lesion (as demonstrated in Figures 4, 5, and 6). For example, the subject with lesion level C4 made greater gains in FVC than the subject at the C6 level. Many factors such as premorbid capacity and motivation may have influenced performance.

Fugl-Meyer et al ${ }^{10}$ found no correlation between PFT values and lesion level apart from ERV which had a correlation of 0.76 . Loveridge et al ${ }^{11}$ studied breathing patterns in 14 chronic $\mathrm{C} 6$ and $\mathrm{C} 7$ quadriplegic subjects, and found no correlation between the level of lesion and the severity of impairment of FVC and IC.

The present study did find a significant correlation (Spearman Product Moment Correlation) between the lesion level and the initial value of FVC (0.86). The correlation coefficient between lesion level and the final value of FVC was only 0.72 , demonstrating that the level of lesion became less of a factor throughout the 10 month period of the study.

There is considerable variation in pulmonary function over the time course of the study as determined by the standard deviation of FEV1, FVC and MVV in Table III. Individual data (Figs 1, 2, 3) demonstrate a profile of variation with some patients improving steadily, and others showing little improvement over time. The FEV1 values of subject 4 , for example, improved $11 \%$ from 90 to 150 days, $52 \%$ from day 150 to 260 , and reached a plateau thereafter.

Pulmonary function, specifically' FEV1.0, improved significantly over the course of this study (Table III). Time is not, however, a predictor of performance as demonstrated by Axen et al, ${ }^{1}$ who found that the correlation coefficient between the initial vital capacity (VC) and rate of change with time was not significant.

There was no correlation between the initial and the final values of FEV1 and FVC, indicating that a patient's initial performance is a poor predictor of his final performance.

In conclusion, pulmonary function testing demonstrated variable recovery of lung function in the subjects tested. Lesion level was a good predictor of average PFT values, but did not emerge as a predictor of the individual's improvement potential. The time course of recovery was variable with some subjects continuing to improve beyond 150 days post injury. Lastly, initial performance in pulmonary function testing is a poor predictor of final performance. 
These finding indicate a role for repeated pulmonary function testing within the spinal cord population to determine individual programmes and progress over time.

\section{Acknowledgement}

This study was supported by funding from the Research Department, Lyndhurst Hospital, Toronto, Ontario, Canada.

\section{References}

1 Axen K, Pineda H, Shunfenthal I, Haas F (1985) Diaphragmatic function following cervical cord injury: neurally mediated improvement. Arch Phys Med Rehabil 66: 219-222.

2 Carter RE (1970-80) Experiences with high tetraplegics. Paraplegia 17: 140-146.

3 Cherniack RM, Raber MD (1972) Normal standards for ventilatory function using an automated wedge spirometer. Am Rev Resp Dis 106: 38-46.

4 Haas F, Azen K, Pineda H, Gandino D, Haas A (1985) Temporal pulmonary function changes in cervical cord injury. Arch Phys Med Rehabil 66: 139-144.

5 Haas A, Lowman EW, Bergofsky EH (1965) Impairment of respiration after spinal cord injury. Arch Phys Med Rehabil 46: 399-405.

6 Ledsome JR, Sharp JM (1981) Pulmonary function in acute cervical cord injury. Am Rev Respir Dis 124: 41-44.

7 McMichan JC, Michel L, Westbrook PR (1980) Pulmonary dysfunction following traumatic quadriplegia. JAMA 243: 528-531.

8 Ohry A, Molho M, Rozin R (1975) Alterations of pulmonary function in spinal cord injured patients. Paraplegia 13: 101-108.

9 Knudson RJ, Slatin RC, Lebowitz MD, Burrows B (1976) The maximal expiratory flow-volume curve normal standards, variability and effects of age. Am Rev Respir Dis 113: 587-600.

10 Pedhauser EJ (1982) Multiple Regression in Behavioural Research. 2nd ed. Holt Reinehart and Winston, New York: 230.

11 Fugl-Meyer AR, Grimby G (1971) Ventilatory function in tetraplegic patients. Scand J Rehab Med 3: $151-160$.

12 Loveridge BM, Dubo HI (1990) Breathing pattern in chronic quadriplegia. Arch Phys Med Rehabil 71: 495-499. 